\title{
Identifying the Neurogenetic Framework of Crohn's Disease Through Investigative Analysis of the Nucleotide-binding Oligomerization Domain- containing Protein 2 Gene Mutation
}

\author{
Md Sakibuzzaman ${ }^{1}$, Syed Ahmad Moosa ${ }^{2}$, Mahabuba Akhter ${ }^{3}$, Ipsita Hamid Trisha ${ }^{4}$, Khandokar A. Talib ${ }^{5}$ \\ 1. Internal Medicine, Sir Salimullah Medical College, Dhaka, BGD 2. Family Medicine, Woodhaven Medical Professional \\ Corporation, Queens Village, USA 3. Biology, Southern Arkansas University, Magnolia, USA 4. Neurology, Sir \\ Salimullah Medical College, Dhaka, BGD 5. Medicine, Sylhet Mag Osmani Medical College and Hospital, Sylhet, BGD
}

Corresponding author: Md Sakibuzzaman, drsakibuzzaman@gmail.com

\begin{abstract}
Among several inflammatory bowel diseases, Crohn's disease is associated with inflammation that may take place in any region of the gastrointestinal tract. The inflammatory process is most commonly associated with the ileum, often spreading deep into the bowel tissues, extending into multiple forms, such as strictures and penetrations. Currently, Crohn's disease has no known cure. Various medical and surgical procedures are used to manage the condition. The underlying mechanisms of the disease are yet to be identified, with recent studies suggesting the influence of genetics, environmental factors, and the possible activity of pathogens. Newer studies also offer strong evidence that suggests a relationship between Crohn's disease and the nucleotide-binding oligomerization domain-containing protein 2 (NOD2) gene, also known as inflammatory bowel disease protein 1 (IBD1) or caspase recruitment domain-containing protein 15 (CARD15). NOD2 is responsible for the mechanism in which the immune system identifies foreign microorganisms through the sensing of pathogen-associated molecular patterns in microorganisms. NOD2 can detect intracellular muramyl dipeptide (MDP) in the bacterial wall, thereby causing an inflammatory response. Three major mutations associated with the NOD2 gene are known to have an influence on Crohn's disease (SNP8, SNP12, and SNP13). This article will discuss a number of studies to identify whether there is a relationship between Crohn's disease and the NOD2 gene.
\end{abstract}

Received 09/03/2019

Review began 09/11/2019 Review ended 09/12/2019 Published 09/17/2019

๑) Copyright 2019 Sakibuzzaman et al. This is an open access article distributed under the terms of the Creative Commons Attribution License CC-BY 3.0., which permits unrestricted use, distribution, and reproduction in any medium, provided the original author and source are credited.
Categories: Genetics, Gastroenterology

Keywords: crohn's disease, nod2, card15, inflammatory bowel diseases

\section{Introduction And Background}

Crohn's disease, first described by Dr. Burrill B. Crohn and colleagues in 1932, affects the entirety of the gastrointestinal (GI) tract, causing inflammation, swelling, and irritation [1]. Although Crohn's disease can affect multiple regions of the GI tract, the most commonly affected part is the ileum, extending from the jejunum up to the ileocecal valve. Crohn's disease is categorized as one of the chronic idiopathic inflammatory diseases [2]. According to Dahlhamer et al.'s 2016 study, the disease had affected three million American citizens by 2015, with a greater susceptibility among adults over 45 years of age [3]. A systematic review by Molodecky et al. found that Crohn's disease was associated with an annual incidence of 3 to 20 cases per 100,000 [4]. Inflammation caused by Crohn's disease has been established as transmural, affecting the entire wall of the gastrointestinal tract, with biopsies often demonstrating the presence of noncaseating granulomas. The disease is associated with a number of symptoms that can vary, including diarrhea, fever, pain in the abdomen, nausea, and vomiting. Crohn's disease exhibits many phenotypes; often, a patient may even progress from one phenotype to another. This phenotypic switching generally starts with the inflammatory process and progresses to either stricturing or penetrating forms. Crohn's disease has no known cure, with patients requiring at least one single surgical resection [5]. The precise pathogenesis of Crohn's disease remains unknown; however, research suggests a variety of environmental and genetic factors associated with increased risks of Crohn's disease [6]. This article will discuss the genetic relationship between Crohn's disease, more specifically, the genetic relationship between Crohn's disease and the nucleotide-binding oligomerization domain-containing 2 (NOD2) gene. The NOD2 gene functions as a synthesizer of NOD2 protein, which plays a significant role in the immune system function. The NOD2 protein is present in different immune cells, such as monocytes and macrophages, which sense peptidoglycan in bacterial cell walls and stimulate a host response. NOD2 mutations are associated with several inflammatory diseases, such as graft versus host disease, Blau syndrome, and Crohn's disease. This type of response reinforces the role that NOD2 gene has in inflammation and host-pathogen interaction [7].

\section{Review}

\section{NOD2 gene regulatory response mechanism}

With each passing moment, the human body comes into frequent and continuous contact with a plethora of 
microorganisms, including pathogens and commensals. In such cases, the immune system acts as the initial line of defense against multiple microbes. However, the dysfunction of the innate immune system can cause infections, as well as inflammation, in addition to autoimmune diseases. The immune system identifies foreign microorganisms through the sensing of pathogen-associated molecular patterns present on and within microorganisms. This is done by a finite number of germline-encoded pattern recognition receptors (PRR), which may exist in either the surfaces of the host cells or inside the intracellular compartments [8]. NOD2 is a cytosolic receptor belonging to the NOD-like receptor family which can detect intracellular muramyl dipeptide (MDP) in the bacterial wall [9]. MDP is available in all bacterial peptidoglycans [10]. NOD2 triggers a pro-inflammatory response when activated. In patients with chronic inflammatory diseases, including Crohn's disease, NOD2 alterations or mutations have been identified [11-16].

Recent studies have found a strong interrelationship between the NOD2 gene, previously known as caspase recruitment domain-containing protein 15 (CARD15), and Crohn's disease. During the beginning of 2001, NOD2 was identified as the first susceptibility gene for Crohn's disease. This theory was first presented by two independent studies [11-12]. Furthermore, in conjunction with these two studies, the consensus among researchers places NOD2 heterozygote alterations with a doubled risk for Crohn's disease, as well as around 20 times the risk for Crohn's disease in NOD2 homozygotes [17-22]. The NOD2 gene interacts with the lipopolysaccharide portion of bacteria, which ultimately induces cellular activation. Yet, the mechanism of Crohn's disease via NOD2 mutation is not entirely understood. Sidiq and colleagues have identified that the NOD2 gene product is present in large quantities among Paneth's cells in the ileum; this coincides with the most commonly affected region in Crohn's disease [23]. A study by Cleynen et al. identified that the age of onset, surgical history of intestinal bowel disease, or extraintestinal manifestations have little or no association, whereas NOD2 has a potential role in the pathology of Crohn's disease based on the family history and disease location in the gastrointestinal tract [24] (Figure 1).

\section{A Pediatric-onset CD}

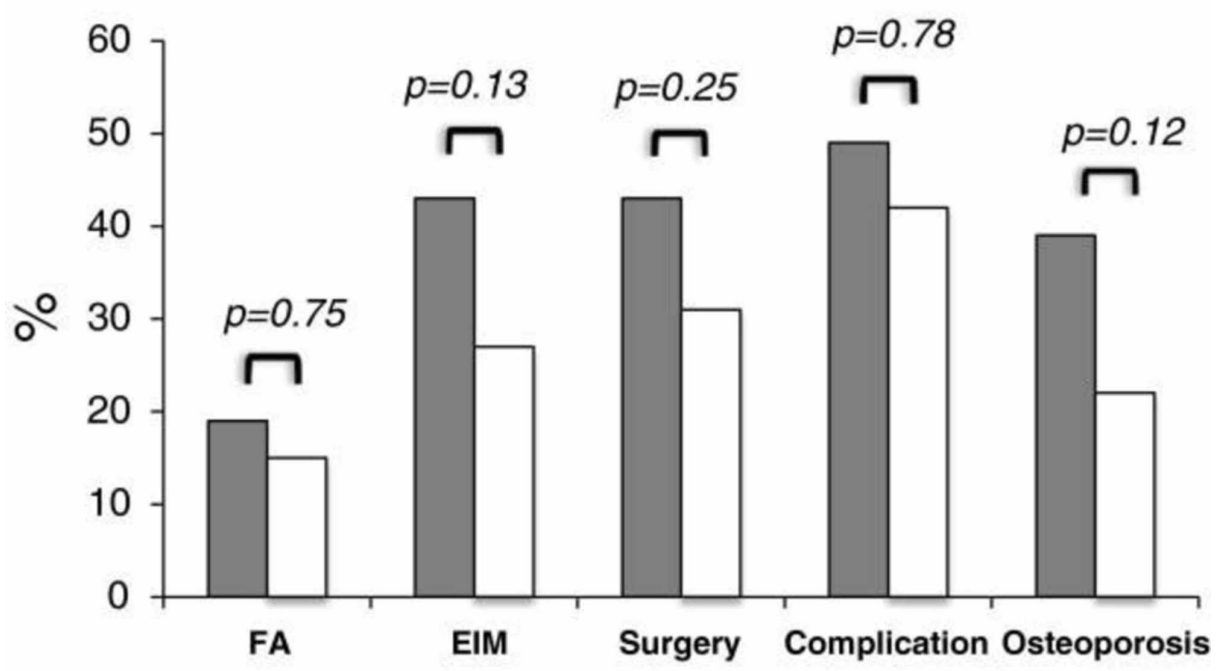

\section{B Adult-onset CD}

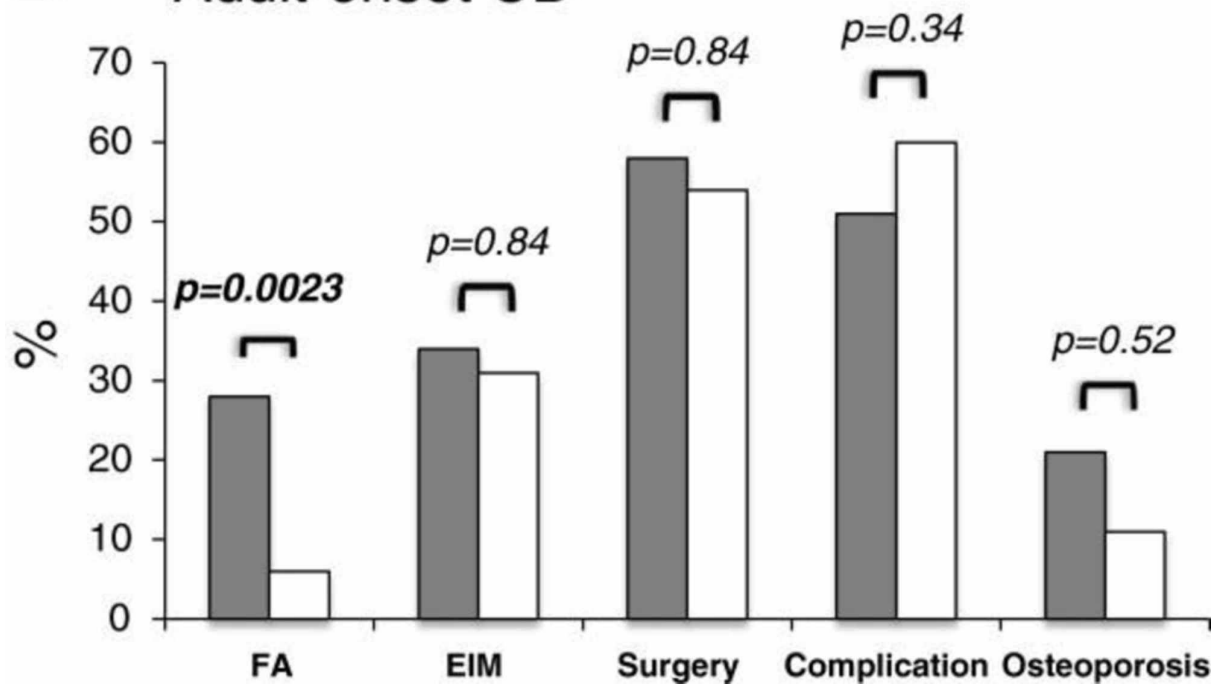


FIGURE 1: The effect of NOD2 gene variants in Crohn's disease (CD) patients (pediatric and adult) on disease behavior

Grey bars represent the NOD2 variant, and white bars represent the NOD2 wild-type alleles. Both are compared with a family history (FA) of intestinal bowel disease, extraintestinal manifestations (EIM), complications, or surgery underwent for Crohn's disease. A p-value less than 0.05 is considered significant [24].

\section{Genetic mutations fostering bowel disease}

The action of NOD2 and its receptor for bacterial pattern recognition offers a valuable link to inflammatory bowel diseases. Approximately 20\% of the genetic susceptibility of Crohn's disease is related to three main mutations (SNP8, SNP12 missense mutations, and SNP13 frameshift mutation) of the NOD2 gene [25]. The analysis of mutations found the NOD2 mutant to lack the last 33 amino acids, resulting in a low nuclear factor kappa B (NFKB) activity [11]. An alternative explanation is that an inborn hypo-responsiveness is a direct result of genetic mutations causing elevated NFkB from an unidentified bacterial lipopolysaccharide (LPS), inducing anti-inflammatory cytokines.

Scudiero et al. conducted a clinical trial on 42 subjects between the ages of $11-69$ years with a mean age of 26.6 years [26]. All subjects were diagnosed with Crohn's disease, with the control group consisting of 65 healthy adults who were not related. The results were in line with another study showing a strong relationship between NOD2 and Crohn's disease [27]. Existing epidemiological and linkage research demonstrates a strong relationship between Crohn's disease and genetic alterations [28-29]. The most common gene associated with the disease is the NOD2 gene [30-31]. The protein function of the NOD2 gene is reduced from polymorphism, which causes an imbalance in the inflammation responses to external stimuli [30, 32]. One allele mutation of NOD2 increased the risk of Crohn's disease up to two to four times, and in instances of a double mutation, the risk was increased up to 20 to 40 times [33]. Lakatos et al. utilized clinical data obtained from a questionnaire completed by the physician to study the correlations between Crohn's disease and NOD2 mutations [34]. The study was conducted among 70 Hungarian males and 72 females with a mean age of 36.2 years, and the results showed that the NOD2 mutations were $29.6 \%$ more prominent in patients diagnosed with Crohn's disease compared to the controls. The study also found that colonic location was affected lesser than the ileal location in patients with the mutation, although the mutation was not influential on the disease characteristics. Lakatos et al. concluded that a higher amount of NOD2 mutations (specifically, the R702W and 3020insC mutations) were present in Hungarian Crohn's disease patients. This finding further suggests that Hungarian patients were less susceptible to G908R mutations. When mutations were prevailing in the Hungarian patients, ileal disease was more common with fibrostenosis and extraintestinal diseases were rare.

There is an increased risk of being diagnosed with Crohn's disease if a patient has a family history of the disease. Around $10-25 \%$ of patients diagnosed with inflammatory bowel disease have a first-degree relative who also has the disease [6]. When geographical backgrounds are considered, the same study identified that the disease is less frequent in African-Americans and Hispanics, whereas Ashkenazi Jews are more susceptible compared to non-Jews. Some clinical studies aimed at identifying the relationship between NOD2 and Crohn's disease in twins show a concordance rate of $20-50 \%$ in monozygotic vs. $10 \%$ in dizygotic twins [35-37].

According to data presented by Hugot et al., four out of 10 Crohn's disease patients are carriers one of the three NOD2 variants [38]. It is important to note here that around $15 \%$ of healthy individuals carry one of the NOD2 variants as well. Other replications may also exist, such as in IBD2, IBD3, and IBD4, for Crohn's disease to develop. Additionally, such areas may also contain NOD2 genes, which demonstrate the possibility of additional factors to be also present (such as interactions with other genes) in addition to NOD2 defects. Such findings prove that a significant amount of additional work is needed to benefit from the relationships identified from NOD2 and Crohn's disease-related studies. Although many studies have identified the potential role of NOD2 in Crohn's disease, multiple other factors can also contribute to increased risks and act as different pathways for Crohn's disease. These factors include various environmental factors, autophagy, epithelial functions, and adaptive immunity [24, 39]. Therefore, the present times are still too early to obtain a noteworthy benefit for clinicians or patients. However, continuous research in the field can offer promising outcomes and possibly a successful cure for Crohn's disease.

\section{Conclusions}

Crohn's disease can affect the entire gastrointestinal tract in any region. The disease is generally managed medically, and at times, patients may require surgical intervention. Although the precise etiology of the disease is unknown, the mechanism of the disease has been identified as a result of a combination of environmental and genetic factors. Strong evidence suggests a relationship between Crohn's disease and the NOD2 gene (or CARD15), which is situated on chromosome 16. Combining the results from multiple 
linkages, clinical, and sequencing studies, it can be concluded that many factors ranging from environmental factors, as well as genetics (particularly, mutations in the NOD2 gene, such as SNP8, SNP12 missense mutations, and SNP13 frameshift mutations), may significantly increase the risk of acquiring the disease.

\section{Additional Information \\ Disclosures}

Conflicts of interest: In compliance with the ICMJE uniform disclosure form, all authors declare the following: Payment/services info: All authors have declared that no financial support was received from any organization for the submitted work. Financial relationships: All authors have declared that they have no financial relationships at present or within the previous three years with any organizations that might have an interest in the submitted work. Other relationships: All authors have declared that there are no other relationships or activities that could appear to have influenced the submitted work.

\section{References}

1. Crohn BB, Ginzburg L, Oppenheimer GD: Regional ileitis: a pathologic and clinical entity . JAMA. 1932, 99:1323-29. 10.1001/jama.1932.02740680019005

2. Loftus EV Jr, Silverstein MD, Sandborn WJ, Tremaine WJ, Harmsen WS, Zinsmeister AR: Crohn's disease in Olmsted County, Minnesota, 1940-1993: incidence, prevalence, and survival. Gastroenterology. 1998, 114:1161-68. 10.1016/s0016-5085(98)70421-4

3. Dahlhamer JM, Zammitti EP, Ward BW, Wheaton AG, Croft JB: Prevalence of inflammatory bowel disease among adults aged $\geqslant 18$ years-United States, 2015. MMWR Morb Mortal Wkly Rep. 2016, 65:1166-69. 10.15585/mmwr.mm6542a3

4. Molodecky NA, Soon IS, Rabi DM, et al.: Increasing incidence and prevalence of the inflammatory bowel diseases with time, based on systematic review. Gastroenterology. 2012, 142:46-54.e42. 10.1053/j.gastro.2011.10.001

5. Cheifetz AS: Management of active Crohn disease. JAMA. 2013, 309:2150-58. 10.1001/jama.2013.4466

6. Ng SC, Bernstein CN, Vatn MH, et al.: Geographical variability and environmental risk factors in inflammatory bowel disease. Gut. 2013, 62:630-49. 10.1136/gutjnl-2012-303661

7. Al Nabhani Z, Dietrich G, Hugot JP, Barreau F: Nod2: the intestinal gate keeper. PLoS Pathog. 2017, 13:e1006177. 10.1371/journal.ppat.1006177

8. Takeuchi O, Akira S: Pattern recognition receptors and inflammation. Cell. 2010, 140:805-20. 10.1016/j.cell.2010.01.022

9. Proell M, Riedl SJ, Fritz JH, Rojas AM, Schwarzenbacher R: The Nod-like receptor (NLR) family: a tale of similarities and differences. PLoS One. 2008, 3:e2119. 10.1371/journal.pone.0002119

10. Kawai T, Akira S: The roles of TLRs, RLRs and NLRs in pathogen recognition . Int Immunol. 2009, 21:317-37. 10.1093/intimm/dxp017

11. Hugot JP, Chamaillard M, Zouali H, et al.: Association of NOD2 leucine-rich repeat variants with susceptibility to Crohn's disease. Nature. 2001, 411:599-603. 10.1038/35079107

12. Ogura Y, Bonen DK, Inohara N, et al.: A frameshift mutation in NOD2 associated with susceptibility to Crohn's disease. Nature. 2001, 411:603-606. 10.1038/35079114

13. Kanazawa N, Okafuji I, Kambe N, et al.: Early-onset sarcoidosis and CARD15 mutations with constitutive nuclear factor-kappaB activation: common genetic etiology with Blau syndrome. Blood. 2005, 105:1195-97. 10.1182/blood-2004-07-2972

14. Philpott DJ, Sorbara MT, Robertson SJ, Croitoru K, Girardin SE: NOD proteins: regulators of inflammation in health and disease. Nat Rev Immunol. 2014, 14:9-23. 10.1038/nri3565

15. Dugan J, Griffiths E, Snow P, et al.: Blau syndrome-associated Nod2 mutation alters expression of fulllength NOD2 and limits responses to muramyl dipeptide in knock-in mice. J Immunol. 2015, 194:349-57. 10.4049/jimmunol.1402330

16. Feerick CL, McKernan DP: Understanding the regulation of pattern recognition receptors in inflammatory diseases - a 'Nod' in the right direction. Immunology. 2017, 150:237-47. 10.1111/imm.12677

17. Lu C, Waugh A, Bailey RJ, et al.: Crohn's disease genotypes of patients in remission vs relapses after infliximab discontinuation. World J Gastroenterol. 2012, 18:5058-64. 10.3748/wjg.v18.i36.5058

18. Naser SA, Arce M, Khaja A, Fernandez M, Naser N, Elwasila S, Thanigachalam S: Role of ATG16L, NOD2 and IL23R in Crohn's disease pathogenesis. World J Gastroenterol. 2012, 18:412-24. 10.3748/wig.v18.i5.412

19. Chen Y, Wang C, Liu Y, et al.: miR-122 targets NOD2 to decrease intestinal epithelial cell injury in Crohn's disease. Biochem Biophys Res Commun. 2013, 438:133-39. 10.1016/j.bbrc.2013.07.040

20. Boukercha A, Mesbah-Amroun H, Bouzidi A, et al.: NOD2/CARD15 gene mutations in North Algerian patients with inflammatory bowel disease. World J Gastroenterol. 2015, 21:7786-94. 10.3748/wjg.v21.i25.7786

21. Martínek L, Kupka T, Simova J, et al.: NOD2/CARD15 mutations and the risk of reoperation in patients with Crohns disease. Rozhl Chir. 2015, 94:242-46.

22. Salkic NN, Adler G, Zawada I, et al.: NOD2/CARD15 mutations in Polish and Bosnian populations with and without Crohn's disease: prevalence and genotype-phenotype analysis. Bosn J Basic Med Sci. 2015, 15:67-72. 10.17305/bjbms.2015.348

23. Sidiq T, Yoshihama S, Downs I, Kobayashi KS: Nod2: a critical regulator of ileal microbiota and Crohn's disease. Front Immunol. 2016, 7:367. 10.3389/fimmu.2016.00367

24. Cleynen I, Boucher G, Jostins L, et al.: Inherited determinants of Crohn's disease and ulcerative colitis phenotypes: a genetic association study. Lancet. 2016, 387:156-67. 10.1016/S0140-6736(15)00465-1

25. Salem M, Seidelin JB, Rogler G, Nielsen OH: Muramyl dipeptide responsive pathways in Crohn's disease: from NOD2 and beyond. Cell Mol Life Sci. 2013, 70:3391-404. 10.1007/s00018-012-1246-4 
26. Scudiero O, Nigro E, Monaco ML, et al.: C.802C >T NOD2/CARD15 SNP is associated to Crohn's disease in Italian patients. Genetics. 2015, S7:005. 10.4172/2161-1041.S7-005

27. Schäffler H, Rohde M, Rohde S, et al.: NOD2- and disease-specific gene expression profiles of peripheral blood mononuclear cells from Crohn's disease patients. World J Gastroenterol. 2018, 24:1196-205. 10.3748/wjg.v24.i11.1196

28. Chua KH, Hilmi I, Ng CC, Eng TL, Palaniappan S, Lee WS, Goh KL: Identification of NOD2/CARD15 mutations in Malaysian patients with Crohn's disease. J Dig Dis. 2009, 10:124-30. 10.1111/j.17512980.2009.00374.x

29. Ek WE, D'Amato M, Halfvarson J: The history of genetics in inflammatory bowel disease . Ann Gastroenterol. 2014, 27:294-303.

30. Strober W, Watanabe T: NOD2, an intracellular innate immune sensor involved in host defense and Crohn's disease. Mucosal Immunol. 2011, 4:484-95. 10.1038/mi.2011.29

31. Long WY, Chen L, Zhang CL, Nong RM, Lin MJ, Zhan LL, Lv XP: Association between NOD2/CARD15 gene polymorphisms and Crohn's disease in Chinese Zhuang patients. World J Gastroenterol. 2014, 20:4737-44. 10.3748/wjg.v20.i16.4737

32. Bhullar M, Macrae F, Brown G, Smith M, Sharpe K: Prediction of Crohn's disease aggression through NOD2/CARD15 gene sequencing in an Australian cohort. World J Gastroenterol. 2014, 20:5008-16. 10.3748/wjg.v20.i17.5008

33. van der Linde K, Boor PP, Houwing-Duistermaat JJ, Crusius BJ, Wilson PJ, Kuipers EJ, de Rooij FW: CARD15 mutations in Dutch familial and sporadic inflammatory bowel disease and an overview of European studies. Eur J Gastroenterol Hepatol. 2007, 19:449-59. 10.1097/01.meg.0000236887.44214.6a

34. Lakatos L, Lakatos PL, Willheim-Polli C, et al.: NOD2/CARD15 mutations and genotype-phenotype correlations in patients with Crohn's disease. Hungarian multicenter study (Article in Hungarian). Orv Hetil. 2004, 145:1403-11.

35. Thompson NP, Driscoll R, Pounder RE, Wakefield AJ: Genetics versus environment in inflammatory bowel disease: results of a British twin study. BMJ. 1996, 312:95-96. 10.1136/bmj.312.7023.95

36. Orholm M, Binder V, Sorensen TI, Rasmussen LP, Kyvik KO: Concordance of inflammatory bowel disease among Danish twins. Results of a nationwide study. Scand J Gastroenterol. 2000, 35:1075-81. 10.1080/003655200451207

37. Halfvarson J, Bodin L, Tysk C, Lindberg E, Jarnerot G: Inflammatory bowel disease in a Swedish twin cohort: a long-term follow-up of concordance and clinical characteristics. Gastroenterology. 2003, 124:1767-73. 10.1016/s0016-5085(03)00385-8

38. Hugot JP, Laurent-Puig P, Gower-Rousseau C, et al.: Mapping of a susceptibility locus for Crohn's disease on chromosome 16. Nature. 1996, 379:821-23. 10.1038/379821a0

39. Wang MH, Achkar JP: Gene-environment interactions in inflammatory bowel disease pathogenesis . Curr Opin Gastroenterol. 2015, 31:277-82. 10.1097/MOG.0000000000000188 